\title{
Senhora dos afogados: reescritura de um clássico brasileiro
}

\author{
Igor de Almeida Silva \\ Universidade de São Paulo - Doutorando em Artes Cênicas \\ Projeto "Companhia Teatro de Seraphim: a Vertigem das Máscaras" \\ Pesquisa em andamento $-2^{\circ}$ ano do curso \\ Teoria do Teatro \\ Ingrid Dormien Koudela \\ Bolsista CAPES \\ Professor, pesquisador, ensaísta e ator
}

Resumo: Este artigo propõe um estudo do espetáculo Senhora dos afogados, de Nelson Rodrigues, direção Antonio Cadengue, pela Companhia Teatro de Seraphim (CTS), estreado em 1993, no Recife, em que se pretende mostrar os princípios norteadores de seu projeto de encenação, nos quais se percebe uma discussão a respeito do que poderia ser um "clássico" no teatro brasileiro.

Palavras-chave: análise de espetáculos, teatro brasileiro, clássico

Title: Senhora dos afogados: the rewriting of a Brazilian classic

Abstract: This paper analyses the mounting of Nelson Rodrigues' Senhora dos afogados, directed by Antonio Cadengue, Companhia Teatro de Seraphim (CTS), premiered in 1993 in Recife. It intends to show some principles of that production's directing project, which comprises a discussion about what a "classic" in the Brazilian theater could be.

Keywords: analysis, Brazilian theater, classic

Título: Senhora dos afogados: reescritura de un clásico brasileño

Resumen: El presente artículo propone un estudio del espectáculo Senhora dos afogados, de Nelson Rodrigues, dirección de Antonio Cadengue, por la Compañía Teatro de Seraphim (CTS), estrenado en 1993, en Recife, en el que se pretende mostrar los principios norteadores de su proyecto de puesta en escena, en los que se percibe una discusión en torno a lo que podría ser llamado de un "clásico" en el teatro brasileño.

Palabras-clave: análisis de espectáculos, teatro brasileño, clásico

I

Neste texto, pretende-se realizar um exercício de análise de espetáculo, a partir da montagem de Senhora de dos afogados, de Nelson Rodrigues, encenação de Antonio Cadengue, pela Companhia Teatro de Seraphim, no Recife, em 1993. Em atividade desde 1990, este grupo pernambucano é nosso objeto de estudo no doutorado e o espetáculo em questão faz parte do corpus da tese, que tem como objeto principal a análise de alguns espetáculos matrizes (Em nome do desejo, 1990/1992; Senhora dos 
Afogados, 1993; Os biombos, 1995; A filha do teatro, 2007) a fim de poder identificar aspectos recorrentes de sua poética cênica.

Como instrumental para a análise dos espetáculos, utilizar-se-á as contribuições da semiologia do teatro de tradição francesa, particularmente os livros $A$ análise dos espetáculos (2003), Vers une théorie de la pratique théâtrale: voix et images de la scène (2007) e O teatro no cruzamento das culturas (2008), de Patrice Pavis, e o livro Lire le théatre II - L'École du spectateur (1996), de Anne Ubersfeld. A partir deste referencial teórico preliminar, será possível identificar as variações da estética e dos procedimentos de criação de Antonio Cadengue e de sua Companhia Teatro de Seraphim. Como afirma Patrice Pavis, a semiologia do teatro encontra-se em um cruzamento de teorias e práticas, criando para si mesma o que ele chama de um oximoro teórico. Esses “oximoros põem em questão e em crise as operações clássicas da semiologia, tais como a fabricação de signo, a tradução em significados, a leitura dos signos etc. Sugerem a superação, ou pelo menos, o reexame, de outras oposições" (PAVIS, 2003, p. 305), como por exemplo, a de diacronia e sincronia: "As análises de espetáculos podem também examinar como a encenação se inscreve na história e como a história se inscreve nela, por camadas sucessivas ou manchas sobrepostas" (PAVIS, 2003, p. 305).

A partir da semiologia teatral, entende-se a cena como um complexo sistema de signos, que só adquire significação por meio da articulação de uns com os outros. Dessa maneira, pretende-se analisar o espetáculo destacado em suas relações internas, ou seja, entre texto e cena, corpo e espaço, gesto e voz, além de suas articulações com outros espetáculos da Companhia Teatro de Seraphim e com seu respectivo contexto (histórico e cultural), na época de sua estreia.

No entanto, a semiologia do teatro (e outras teorias que venham a contribuir para este trabalho) tem uma função instrumental, como forma de permitir um mapeamento de procedimentos e aspectos do trabalho do grupo pernambucano, a fim de que se possam levantar outras questões referentes à estética teatral e ao teatro brasileiro. No estágio atual da pesquisa, após um estudo de críticas, programas de espetáculos, entrevistas, artigos produzidos pelo encenador do grupo, entre outros documentos, pôde-se constatar a recorrência da máscara enquanto tema e forma de seus espetáculos e do conjunto de ideias teatrais do grupo identificadas por meio destes documentos. 
Como exemplo, ao final do projeto cultural Seraphins Revisões, em 1992, Cadengue publica um artigo no Jornal do Commercio, intitulado "Seraphins: encontrarse":

\begin{abstract}
No jogo que no palco se instaura, as quatro montagens teceram desvendamentos e, ao mesmo tempo, aprofundaram os artifícios próprios do teatro, na intenção de pôr a nu as máscaras: das sociais às metafísicas. Esta ideia nos obsessiona e determina em muito a escolha de nosso repertório e de nossa práxis.

Envolver-se tanto com o teatro como o fazemos - e vimos fazendo - remetenos sem que queiramos, a um texto de Pirandello, Trovarsi, onde a personagem central do enredo, uma atriz, se realiza na imagem de cada uma das personagens que interpreta, vivendo intensamente a ficção - dentro e fora do palco - num intraduzível processo de transfiguração. Sem o teatro, enfim, ela não existe. Suas últimas falas na peça nos diz: "Verdade é somente que é preciso criar-se, criar! E assim somente nos encontramos". Fazemos nossas estas palavras, por traduzir toda busca de encontro conosco mesmo e com os outros - razão de nosso trabalho. Mas não se conclua que nosso projeto implica numa estéril estetização da vida, mas na tentativa de construí-la como ininterrupto projeto de decifração de nossa contemporaneidade e mesmo de sua transformação.
\end{abstract}

Logo no primeiro parágrafo, o encenador destaca a intenção de pôr a nu as máscaras, tanto as sociais quanto as metafísicas. Essa noção da máscara está relacionada com a concepção de pluralidade do ser humano. Aspecto central da obra de Luigi Pirandello, autor a quem Cadengue faz referência logo em seguida nesse artigo, identificando-o de modo espelhar a própria identidade-máscara da CTS. Aliás, um dos primeiros dramaturgos encenados por Cadengue, no final dos anos 1970, quando ele monta Esta noite se improvisa com a Companhia Praxis Dramática.

Segundo Anatol Rosenfeld, tratando da questão da máscara na obra de Pirandello, "A vida social impõe ao indivíduo uma forma fixa, tornada em máscara. O fluxo da existência necessita desta fixação para não se dissolver em caos, mas ao mesmo tempo o papel imposto ou adotado estrangula e sufoca o movimento da vida" (1976, p. 12). A razão então impõe ficções, falsas ilusões, que se absorvem no decurso da vida, mas que, aos poucos, adquirem uma forma rígida, artificial e opressora. Porém, essa máscara também se torna parte essencial da vida. Ela passa a expressar "uma verdade essencial que os homens não conseguem dizer nem viver na vida cotidiana, mas que podem atingir no exercício do teatro" (DORT, 1977, p. 237).

Sob diferentes tempos, ambientes e estéticas, os temas da identidade e da máscara são a tônica de seus espetáculos. Percebe-se também uma discussão sobre a 
sociedade e a cultura brasileira. Talvez seja possível compreender esses aspectos das ideias teatrais do grupo por meio das palavras de seu encenador:

Eu sou urbano. Cosmopolita. O que eu faço é uma psicanálise cultural. E não faço por modismo, nem pra aquilo ser devorado pelo 'sul maravilha'. O que as pessoas do sul e do sudeste esperam de nós é sempre um Antonio Nóbrega. Aliás, excelente performer. A imagem que eles esperam é sempre aquilo que supõem ser ou ter a cara do Nordeste. Esta cara eu não quero ter. Porque ser brasileiro é sempre ser outro, como dizia Paulo Emílio Salles Gomes. É a identidade de não ter identidade, essa máscara em que me percebo e percebo em nós brasileiros, essa maleabilidade, essa plástica, que somos nós. E querem sempre nos dar uma máscara permanente. E foi contra essa máscara que eu acabei me insurgindo ao longo desses anos. E acho que nessa questão tem um diálogo enorme com o teatro, que é ser o que não se é (CADENGUE, 2001, p. 114-115).

No que concerne à máscara e à identidade, Cadengue nega-se a compactuar com as imagens-máscaras que se projetam sobre ele. Faz da máscara um jogo sinuoso, uma vertigem, de desvelamento e sobreposição de novas máscaras que, para ele, são a própria identidade brasileira. Faz da máscara a própria essência da cultura brasileira. Como em Pirandello, é apenas pela representação que nos encontramos.

\section{II}

No momento, uma questão central para a tese é averiguar em que medida e de que maneira estas questões vinculadas à máscara e à identidade se manifestam formalmente na cena. Esta pergunta é a que orienta nossa perspectiva de estudo acerca da montagem de Senhora dos afogados neste texto.

No espetáculo, utiliza-se o palco nu, em que os diferentes tempos e espaços ficcionais são estabelecidos pelos corpos dos atores, com o auxílio dos demais elementos da cena, como luz, sonoplastia, figurino e adereços, resultando em uma visualidade barroca. 


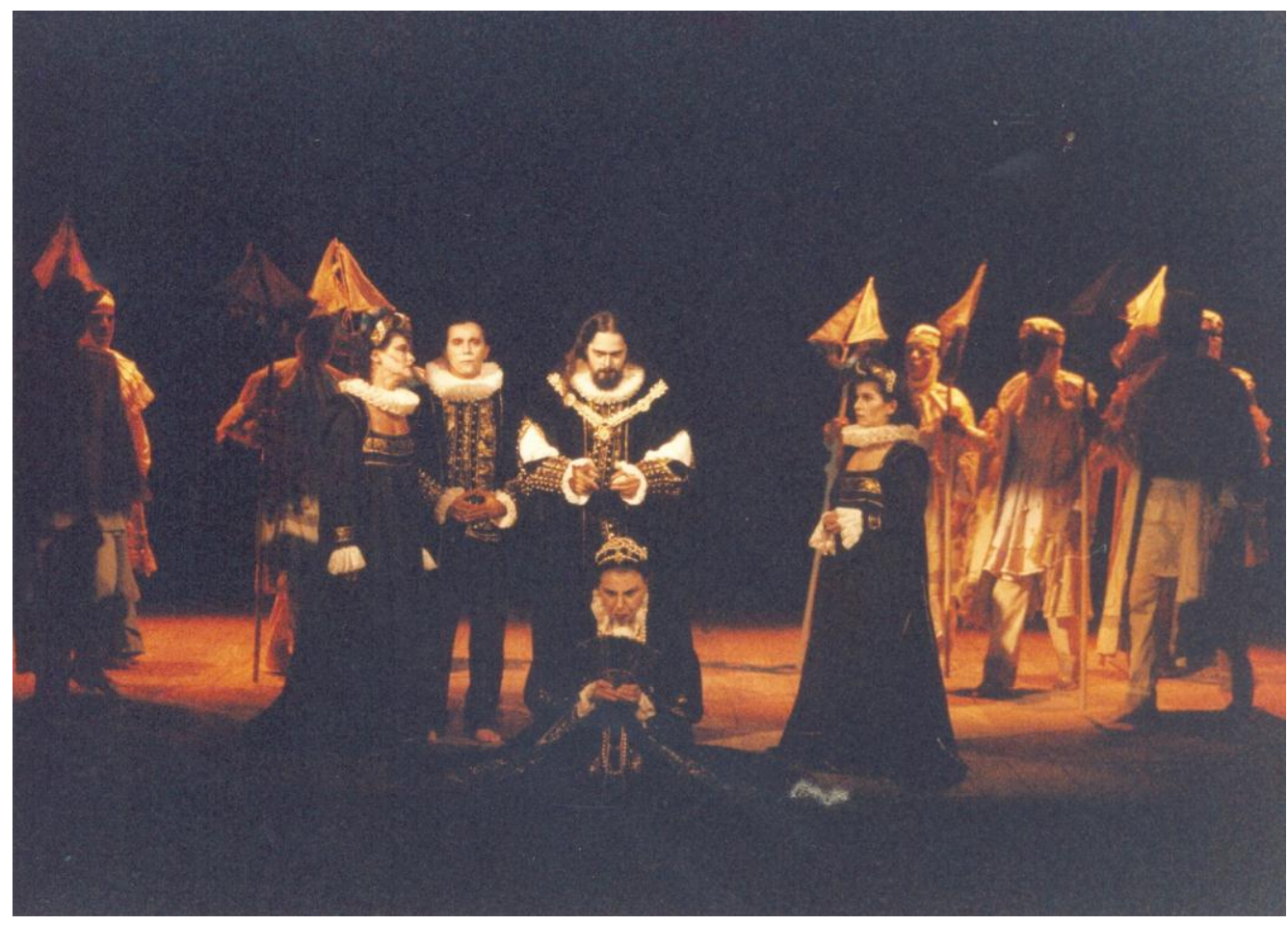

Retomando o mito de Electra, a peça mostra o amor obsessivo de uma filha (Moema) para com seu pai (Misael), levando-a ao assassínio de todos os membros de sua família, a fim de que apenas ela possa partilhar da presença do pai, tornando-se assim sua única mulher. Acentuando os aspectos míticos e ritualísticos do texto, a cena se veste de tons negros e escarlates, constituindo uma cena inspirada no renascimento inglês, no século de ouro espanhol e no teatro oriental. O coro, ostentando máscaras em forma de barcos, veste-se em tons de terra, evocando a praia, o mar onipresente, que ameaça constantemente invadir a casa da família Drummond. Este núcleo da peça possui indumentária em veludo negro, com detalhes dourados, rufos brancos e, no caso das mulheres, adornadas de pérolas, ao mesmo tempo luxuosa e lúgubre. Já as mulheres do cais, numa inversão da moralidade doentia do núcleo familiar da trama, trajam figurinos no mesmo estilo do da família Drummond; porém, vermelhos, como se conciliassem em si mesmas Eros e Tânatos, quando atravessam o palco, de modo processional, entoando cânticos fúnebres e imprecações contra o patriarca Misael, assassino de uma antiga prostituta. Segundo o crítico Edelcio Mostaço, esse "amaneiramento estilístico" da encenação imprime à peça "o tônus de uma tragédia shakespeareana", no qual se reforça o grotesco e o sublime de suas situações: "Como se uma releitura de Racine e Shakespeare, a curiosa obra de Stendhal que procurou 
conciliar a hierática nobreza do século 17 francês com a grandiosidade das paixões do renascimento inglês, tivesse prestado ao encenador o dom de uma inspiração divina" (MOSTAÇO, 1996, p. 43).

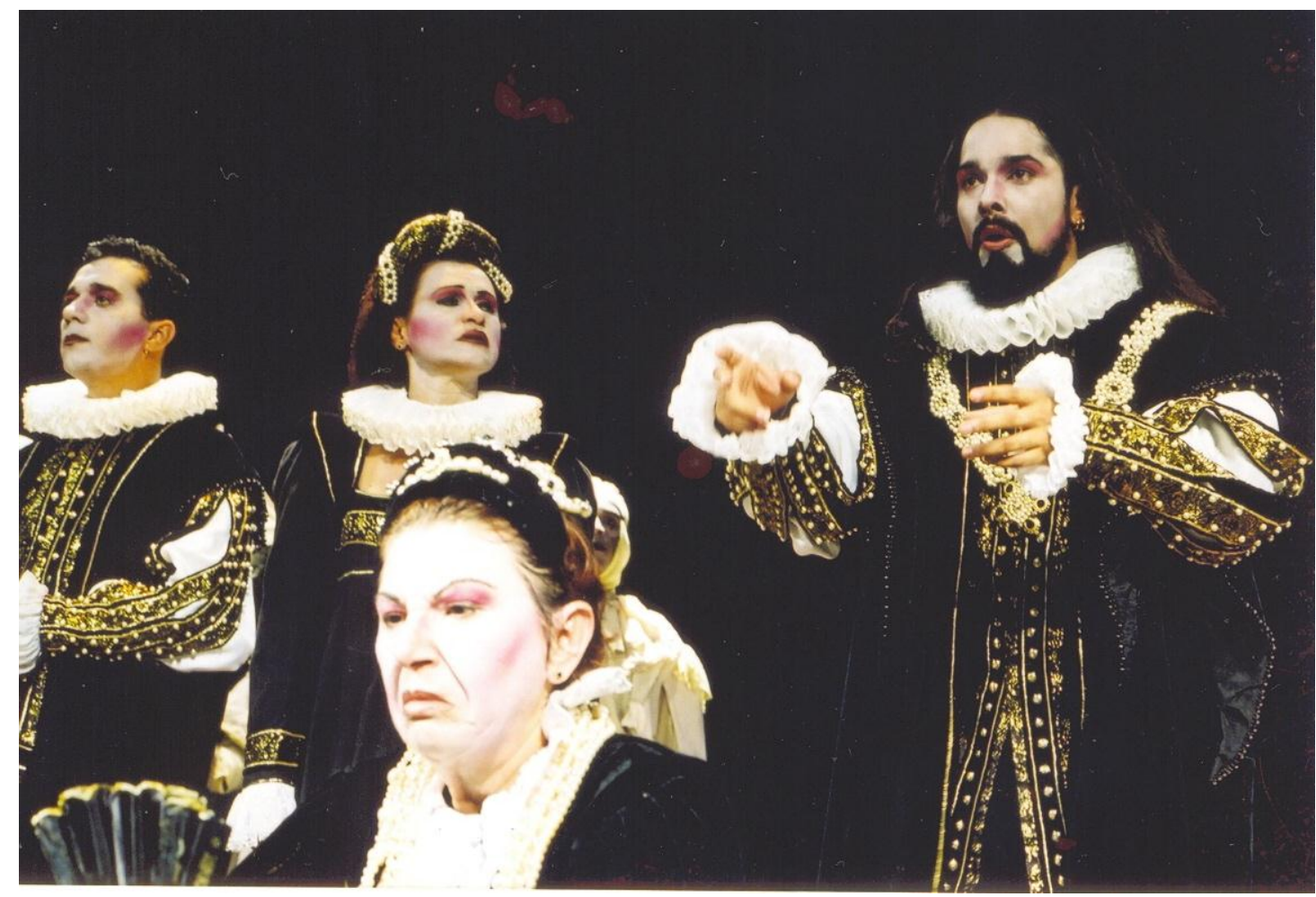

O encenador emprega exclusivamente a luz e os corpos dos atores (amparado por suntuosa indumentária) para criar as ambiências da representação. Os diversos espaços da casa (a sala, o quarto de D. Eduarda e Misael, o quarto da avó) são sugeridos pelas diferentes disposições espaciais do coro. Ou seja, o corpo dos atores irradia $o$ espaço cênico (PUPO, 2001, p. 183), ocupando e criando o tempo-espaço ficcional da representação. Mesmo que permaneçam em posições estatuárias, espectrais, deslocamse constantemente na cena, imprimindo mobilidade e plasticidade ao espetáculo. Além disso, o coro assume a função de close na cena, num procedimento de cineficação interna do espetáculo. Nos seus deslocamentos, para demarcar mudanças de cena e também espaciais, muitas vezes seus corpos e seus olhos estão voltados para determinados pontos do palco, onde ocorre a ação, direcionando consequentemente o olhar da plateia, tal como Meierhold, de certo modo, também fazia na peça $O$ inspetor 
geral, em que o olhar dos personagens e o posicionamento dos seus corpos conduziam a atenção do espectador na cena.

\section{III}

Pode-se dizer que, com esta montagem, o encenador dá o tratamento de um clássico à obra de Nelson Rodrigues. Em entrevista concedida ao Instituto Itaú Cultural, como parte das comemorações do centenário do dramaturgo, no projeto Ocupação Nelson Rodrigues, o encenador Antonio Cadengue informa que a concepção da encenação surge como resposta a um ato de desprezo à obra de Nelson Rodrigues.

Em 1993, a protagonista do espetáculo, Cira Ramos, intérprete da personagem Moema, propõe a então diretora da Legião Assistencial do Recife, órgão do Governo do Estado, a compra antecipada de ingressos para auxiliar nos custos de produção. No entanto, ao tomar conhecimento do projeto e, sobretudo, do autor que seria encenado, esta senhora informa que não poderia se comprometer por se tratar da montagem de um texto de Nelson Rodrigues, segundo ela, um autor pornográfico cuja obra não despertaria o interesse da burguesia pernambucana afeita apenas aos "clássicos".

É a partir deste repúdio a Nelson que o encenador direciona sua proposta de encenação, passando a concebê-lo então como um "clássico". Nesse sentido, como foi descrito, o encenador situa o espetáculo entre os séculos XVI e XVII, na época do século de ouro espanhol e do renascimento inglês, ou seja, no período áureo do teatro elisabetano e de Shakespeare, o óbvio ululante do que seria um teatro clássico para o gosto médio burguês. Além disso, adapta o texto procurando eliminar aspectos prosaicos que remetessem a uma "oleosidade naturalista", fazendo ressaltar o núcleo arquetípico da trama familiar, seu caráter hierático e mítico. 


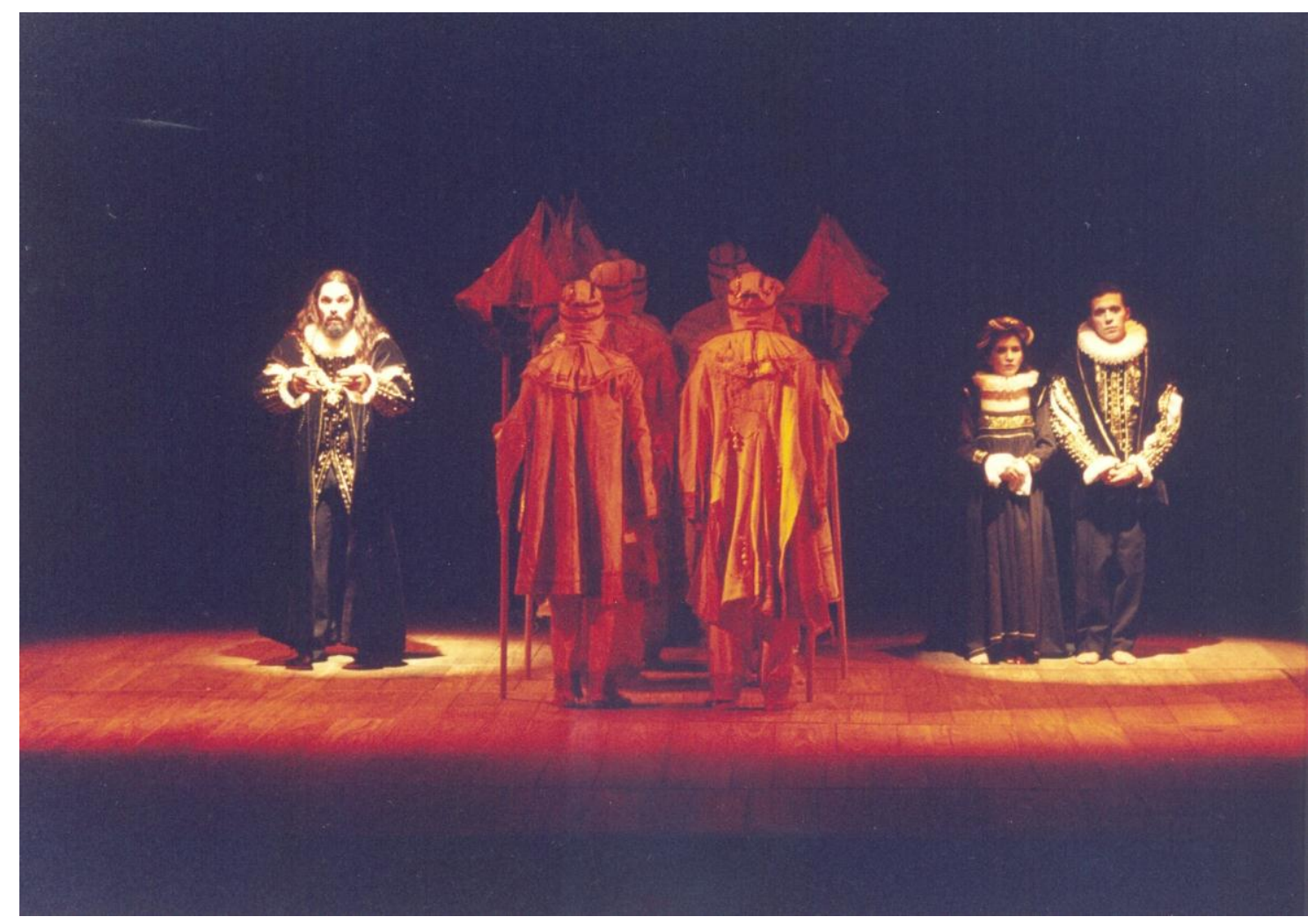

Mas o que seria um clássico? E como representá-lo? Segundo Anne Ubersfeld, de maneira geral, pode-se considerar um clássico "tudo aquilo que, não tendo sido escrito para nós mas para outros, reclama uma 'adaptação' a nossos ouvidos” (2002, p. 9). E, numa concepção mais restritiva, "tudo o que foi escrito numa sociedade e para uma sociedade diferente da nossa" (2002, p. 10). Por isso, a leitura e, por extensão, representação dos clássicos se configura como um ato de des-leitura em que é preciso “des-ler o que foi lido ontem - não que essa leitura tenha se tornado 'falsa' mas é que não é mais para nós" (2002, p. 10). Na prática da encenação, a teórica aponta dois procedimentos básicos de abordagem de um texto clássico: historicizar ou torná-lo intemporal. Em ambos, o objetivo essencial do encenador é encontrar equivalentes contemporâneos para referências do texto que já se tornaram obsoletas aos nossos ouvidos, ou então procurar o que ainda é recorrente para nós, privilegiando ora a diferença, ora uma possível relação, para que se possa evidenciar uma mesma situação de fala, outrora e hoje.

No caso da montagem de Senhora dos afogados pela Companhia Teatro de Seraphim, parece que houve um procedimento inverso: Nelson Rodrigues, um autor do 
século XX, portanto um contemporâneo, cuja encenação, ao invés de aproximá-lo, como ocorreria com um dramaturgo de outra época, torna-o distante, afasta-o para outro tempo e espaço.

Além disso, a encenação faz referências a outras tradições teatrais fora a do drama elisabetano: o teatro clássico francês por meio da elocução projetada dos atores, que tiveram como modelo registros sonoros de atores e atrizes franceses do século XIX e meados do século XX, recitando textos de Racine e Corneille; o teatro grego por meio do tratamento dispensado ao coro de vizinhos, acentuando seu aspecto mítico enquanto uma consciência coletiva que informa sobre o passado e vaticina os membros da família, tornando-se ainda uma representação do mar onipresente que ameaça constantemente a família Drummond; o teatro oriental como aponta o crítico português Manuel João Gomes, do periódico lisboeta Público (quando da passagem do grupo por Portugal dentro do projeto CumpliCidades), que se refere ao epílogo do espetáculo como "um fragmento de Nô, com mortos de regresso à vida" (GOMES, 1994).

Por um lado, esta opção da encenação não deixa de ser polêmica, como se pode constatar no comentário do crítico de cultura Jomard Muniz de Britto: "O pó dos mais sensíveis, espertos e/ cumplíces SERAFINS na/ 'estranha paisagem de metamorfosearse/ numa espécie de museu' (G. Bornheim)/ da Senhora dos Afogados. Ó cidade tão museal!" (1994, p. 44). Supõe-se que, para o crítico, esta arqueologia de formas e tradições teatrais seja um procedimento anacrônico, como se ele congelasse Nelson em um museu da história do teatro.

Por outro lado, ao lançar mão desse amplo leque de referências históricas, culturais e teatrais, o espetáculo tem explicitamente uma feição irônica, sendo quase uma piada lançada contra os detratores do teatro de Nelson (no caso, especificamente, a tal senhora da Legião Assistencial do Recife), ao representá-lo sob a máscara do clássico, ou do que se poderia conceber como um "clássico", entre tantas maneiras diferentes, também elas outras máscaras. A encenação evidencia-se, portanto, enquanto uma máscara, ou melhor, várias máscaras, que se sucedem ao longo do espetáculo, de modo vertiginoso, quase uma vertigem. Mas, ao mesmo tempo, essa é uma piada levada a sério.

Ao fazer atravessar por Nelson Rodrigues diferentes temporalidades e tradições teatrais que obviamente o antecedem, a Companhia Teatro de Seraphim presta-lhe uma homenagem, tornando-o parte (e também representante) desse grande teatro do mundo. 
Trata-se de uma dupla ação: insere a história do teatro na obra de Nelson Rodrigues, ao mesmo tempo em que o torna também parte desta mesma História.

A ideia do clássico surge então numa dupla acepção: clássico como ironia (chiste) e clássico como legitimação (uma piada séria). Talvez não seja possível se pensar na noção de clássico no teatro brasileiro sem levar em consideração estas duas perspectivas (sobretudo a primeira), já que, como diz Paulo Emílio Salles Gomes, somos desprovidos de cultura original: "Não somos europeus nem americanos do norte, mas destituídos de cultura original, nada nos é estrangeiro, pois tudo o é. A penosa construção de nós mesmos se desenvolve na dialética rarefeita entre o não ser e o ser outro" (GOMES, 1980, p. 77).

Senhora dos afogados é certamente um dos mais expressivos espetáculos da Companhia Teatro de Seraphim. Para Edelcio Mostaço, com esta montagem, “o Recife recria uma obra fundamental da dramaturgia nacional digna de figurar na galeria das grandes realizações que o teatro contemporâneo aqui praticado pode exibir, ombreada que está no mesmo patamar estético que delimita os verdadeiros criadores da cena brasileira do nosso tempo" (1996, p. 44).

\section{BIBLIOGRAFIA}

- BRITTO, Jomard Muniz de; ARAÚJO, João Denys. Arrecife do desejo. Rio de Janeiro: Leviatã Publicações, 1994.

- CADENGUE, Antonio. Seraphins: encontrar-se. Jornal do Commercio, Recife, p. 6, 27 jun. 1992.

- _ _ Antonio Cadengue: fogo e fôlego, Folhetim, Rio de Janeiro, Teatro do Pequeno Gesto, n. 11, p. 96-120, set.-dez. 2001. Entrevista concedida a Fátima Saadi, Antonio Guedes, Doris Rollemberg e Walter Lima Torres.

- DORT, Bernard. Genet ou o combate com o teatro. In: O teatro e sua realidade. Trad. Fernando Peixoto. São Paulo: Perspectiva, 1977, p. 225-242.

- FÉRAL, Josette. Les Grecs à la Cartoucherie. La recherche des formes. In: Trajectoires du Soleil: autour d'Ariane Mnouchkine. Paris: Éditions Théâtrales, 1998, p. 199-223.

- GOMES, Manuel João. Nelson, o cruel. Público, Lisboa, 10 set. 1994.

- GOMES, Paulo Emílio Salles. Cinema: trajetória no subdesenvolvimento. Rio de Janeiro: Paz e Terra: Embrafilme, 1980. 
- MOSTAÇO, Edelcio. Nelson Rodrigues: a transgressão. São Paulo: Cena Brasileira, 1996.

- PAVIS, Patrice. A análise dos espetáculos. Trad. Sérgio Sálvia Coelho. São Paulo: Perspectiva, 2003.

- __ Vers une théorie de pratique théâtrale: voix et images de la scène. $4^{\mathrm{e}}$ éd. revue et auguementée. Villeneuve d'Ascq: Presses Universitaires du Septentrion, 2007.

- _ O O teatro no cruzamento das culturas. Trad. Nanci Fernandes. São Paulo: Perspectiva, 2008.

A encenação contemporânea: origens, tendências, perspectivas. Trad. Nanci Fernandes. São Paulo: Perspectiva, 2010.

- PUPO, Maria Lúcia. O lúdico e a construção do sentido. Sala Preta, São Paulo, Escola de Comunicações e Artes, Universidade de São Paulo, n. 1, 2001, p. 181-187.

- RODRIGUES, Nelson. Teatro completo: volume único. Organização geral e prefácio Sábato Magaldi. Rio de Janeiro: Nova Aguilar, 1993.

- ROSENFELD, Anatol. Prefácio. In: Texto/contexto. 3. ed. São Paulo: Perspectiva, 1976, p. 11-17.

- UBERSFELD, Anne. Lire Le théatre II - l'école du spectateur. Paris: Belin, 1996.

A representação dos clássicos: reescritura ou museu. Trad. Fátima Saadi. Folhetim, Rio de Janeiro, Teatro do Pequeno Gesto, n. 13, p. 8-37, abr-jun, 2002. 